Focusing Review

\title{
Development and application of chromatographic methods for glycerolipid analysis
}

\author{
Yutaka Itabashi \\ Faculty of Fisheries Sciences, Hokkaido University \\ 3-3-1 Minato-cho, Hakodate 041-8611, Japan
}

\begin{abstract}
In the past 30 years, chiral-phase high-performance liquid chromatography (HPLC) has progressed from an application practiced by just a few chromatographers to a popular method widely used in many areas of pharmaceutical and biological sciences, including lipid chemistry. Since we demonstrated HPLC resolution of mono- and diacylglycerol enantiomers on chiral stationary phases in the 1980s, the methodology has been extended to the resolution of various synthetic and naturally occurring chiral glycerolipids. Using reversed-phase HPLC, we also demonstrated the successful resolution of 1,2-diacylglycerol regioisomers (reverse isomers), which had remained a major unsolved problem in glycerolipid chromatography. These developments of the methodology permit further expansion of lipidomics and better understanding of lipid metabolism.
\end{abstract}

Keywords: glycerolipid; enantiomer; diastereomer; reverse isomer; derivatization; high-performance liquid chromatography; mass spectrometry

\section{Introduction}

There is no uniformly adopted definition for lipids and it is widely accepted that lipids are fatty acids, their derivatives, and substances related biosynthetically or functionally to these compounds [1]. Glycerolipids -lipids based on glycerol (acylglycerols, phospholipids, glycolipids, etc.) -in living organisms are complex mixtures of different types of molecules that contain stereoisomers and regioisomers. Although the technology of chromatography has advanced rapidly in recent years, there still exist many lipid molecules whose separations are difficult to achieve and physiological significance and biological activities are unknown. Accurate and concise methods for the analysis of lipids are therefore essential for many research studies.

In the present "post-genomic era" the focus of investigation is moving away from gene sequences and interest is gradually returning to the gene products themselves (proteomics). It is well recognized that an understanding of pathophysiological changes that oc- cur in cells and tissues requires complementary profiling of lipidderived metabolic products (lipidomics). This has led to the development of mass spectrometry (MS) -based lipidomics methodology [2,3]. MS, however, is unable to differentiate between enantiomers, and in many instances among regioisomers. This shortcoming is especially obvious in glycerolipids due to the prochiral nature of glycerol [4].

There were two unsolved problems in glycerolipid chromatography in the 1980s, one of which was enantiomer separation and the other regioisomer (reverse isomer) separation. We have solved important aspects of these problems by using chiral-phase HPLC [5] and reversed-phase HPLC [6], respectively. This review describes the chromatographic methods developed for both stereoisomeric and regioisomeric glycerolipids and their applications to lipid research. Readers are referred to earlier comprehensive reviews for background covering chiral analysis of glycerolipids $[4$, 7-14].

Correspondence: Faculty of Fisheries Sciences, Hokkaido University, Hakodate, Hokkaido 041-8611, Japan

Phone \& Fax: +81-138-40-8802

E-mail: yutaka@fish.hokudai.ac.jp 


\section{Nomenclature of glycerolipids}

Glycerol and common fatty acids are achiral compounds that have no chiral centers in their molecules, while glycerolipids become chiral molecules when the $\mathrm{C}-1$ and $\mathrm{C}-3$ positions of the glycerol backbone have different fatty acids, or when the $\mathrm{C}-2$ position makes a chiral center. Almost all of the naturally occurring glycerolipids are chiral and can exist as both enantiomers and diastereomers. The structures of some glycerolipids adopted in this review are shown in Figure 1. Generally, stereoisomers of $2^{\mathrm{n}}$ forms (enantiomers of $2^{n-1}$ forms) exist in molecules having chiral centers
A

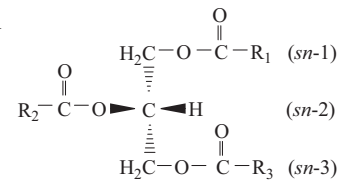<smiles>[R]C(=O)O[C@H]([14CH2]O)[C@@H](CO)OC([R])=O</smiles>

E
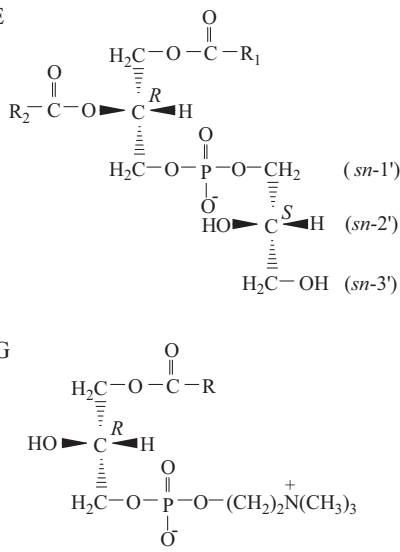<smiles>[R]OC[C@H](O)CO</smiles>

B

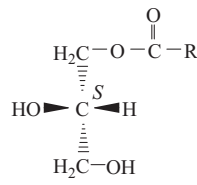

D

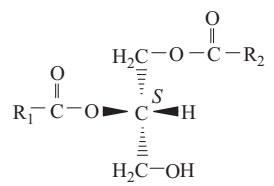

F

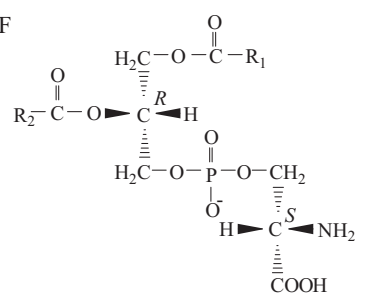

$\mathrm{H}$

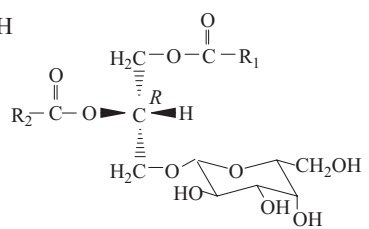

$\mathrm{J}$

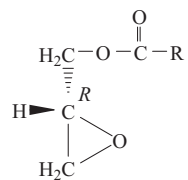

Figure 1. Structures of some chiral glycerolipids. (A) 1,2,3-triacylsn-glycerol (triacylglycerol); (B) 1-acyl-sn-glycerol (monoacylglycerol); (C, D) 1,2-diacyl-sn-glycerol (diacylglycerol reverse isomer, $\mathrm{R}_{1} \neq \mathrm{R}_{2}$ ); (E) 1,2-diacyl-snglycero-3-phospho-1'-sn-glycerol (phosphatidylglycerol, PtdGro); (F) 1,2-diacyl-sn-glycero-3-phospho-L-serine (phosphatidylserine, PtdSer); (G) 1-acyl-2-hydroxy-snglycero-3-phosphocholine (lysophosphatidylcholine, lyso-PtdCho); (H) 1,2-diacyl-[ß-D-galactopyranosyl-(1', $\rightarrow 3$ ) ] -sn-glycerol (monogalactosyldiacylglycerol, MGDG); (I) 1-alkyl-sn-glycerol (glyceryl ether); (J) $(R)$ 1-acyl-2,3-epoxypropane (glycidol fatty acid ester). of $\mathrm{n}$ forms. For example, one set of enantiomers can exist for 1,2diacylglycerol and 1 (and 2)-lysophosphatidylcholine (lyso-Ptd Cho), in which only the C-2 of the glycerol skeleton is a chiral center. Four stereoisomers (enantiomers of 2 sets) can exist for phosphatidylglycerol (PtdGro) and phosphatidylserine (PtdSer), which have two chiral centers in their molecules.

The steric configuration of glycerol-based lipids is usually represented by an $s n$ (stereospecific numbering) notation rather than $R / S$ in the Cahn-Ingold-Prelog system for designating absolute configuration. When the secondary hydroxyl group of an $(S)$ glycerol derivative is put in the left side of C-2 in a Fisher projection, the top and bottom carbons are made to be $\mathrm{C}-1$ and $\mathrm{C}-3$, respectively, and the prefix " $s n$ " is placed before the stem-name of the compound [15]. When compounds have two glycerol backbones, such as PtdGro, C-1' and C-3' are replaced for the second glycerol backbone, similar to the manner described above. According to this notation, 1,2-diacyl-sn-glycerol is $S$ (Figure $1 \mathrm{C}, 1 \mathrm{D}$ ) and its enantiomer, 2,3-diacyl-sn-glycerol, corresponds to $R$. Similarly, 1,2-diacyl-sn-glycero-3-phospho-1'-sn-glycerol fits with $R, S$ (Figure $1 \mathrm{E}$ ), and one of the diastereomers, 1,2-diacyl-sn-glycero-3 -phospho-3'-sn-glycerol, corresponds to $R, R$. It should be noted that although the steric configuration at C-2 of 1,2-diacyl-snglycerol is the same as that of 1,2-diacyl-sn-glycero-3-phospho-1'$s n$-glycerol, the $R / S$ notation reverses each other. In the case of the 3,5-dinitrophenylurethane (3,5-DNPU) and 1(2)-anthrylurethane derivatives of 1,2-diacylglycerol, 1-alkylglycerol, etc., the $R / S$ notation is opposite from that of the original compounds. In addition to enantiomers, natural glycerolipids containing 1,2-diacyl-snglycerol moiety can also exist as regioisomers (reverse isomers), such as 1-palmitoyl-2-linoleoyl-sn-glycerol (16:0-18:2) and 1linoleoyl-2-palmitoyl-sn-glycerol (18:2-16:0) (see Figure 1 C, 1 D).

\section{Chiral-phase HPLC of stereoisomeric glycerolipids}

3.1 Chiral stationary phases (CSP) for glycerolipid analysis

There are a number of different materials employed as CSP. According to Taylor and Maher [16], these materials are classified into six types based on separation principles: ligand exchange phases, charge transfer packings, asymmetric strand packings (brush-type CSP or Pirkle-type CSP), chiral cavity packings, CSP based on polymers, and silica-bound protein CSP. Of these six, the asymmetric strand packings (low molecular weight CSP) and CSP based on polymers (synthetic and natural macromolecules, such as polymethacrylate, polymethacrylamide, cellulose, amylose and their derivatives) are effective for enantiomer separation of glycerolipids. Generally, polycyclic aromatic compounds containing naphthyl or anthryl groups as $\pi$ donors form charge-transfer complexes with aromatic rings having electron-withdrawing substitu- 

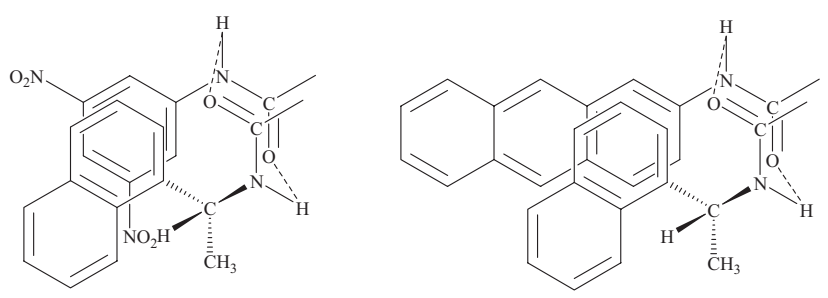

Figure 2. Possible interactions between $(R)$-1-(1-naphthyl)ethylamine CSP and glycerolipid derivatives. (A) 3,5dinitrophenylurethane, (B) 2-anthrylurethane. From [13].

ents such as nitro or cyano groups. We showed that this interaction could also be formed between a naphthyl group and an anthryl group, which would serve as an electron accepter and a donor, respectively [17,18]. In this case, the formations of additional hydrogen-bonding and dipole-dipole stacking between solutes and CSP would better separate the enantiomers. Therefore, if these interactions do not occur between enantiomers and CSP, it might be possible to make them occur by converting them into the appropriate derivatives using achiral reagents. We have found that this derivatization method is very effective for enantiomer separation of chiral glycerolipids containing hydroxyl or amino groups (see Figure 1). Figure 2 illustrates the possible interactions between the 1-(1-naphthyl)ethylamine moiety in CSP and the 3,5dinitrophenylurethane (3,5-DNPU) and 2-anthrylurethane moieties of the glycerolipid derivatives. Enantiomer resolution on Pirkletype CSPs, which consist of relatively small molecular weight chiral substances bonded to silica, is due mainly to attractive interactions between solutes and CSP, i.e., hydrogen-bonding, $\pi-\pi$ complexing, and dipole stacking [19]. The 1-(1-naphthyl)ethylamine CSP has the ability to serve as either a donor or an acceptor in hydrogen-bonding and $\pi-\pi$ complexing and to participate in dipole stacking. Thus, the diastereomeric hydrogen-bonding association, $\pi$ $-\pi$ donor-acceptor interaction, and dipole-dipole interaction between CSP and solutes are probably the major factors contributing to the separation of the derivatives of enantiomeric glycerolipids. In this case, better enantiomer separation is obtained for 3,5-DNPU than for 2-anthrylurethane [13]. This suggests that the chargetransfer complex formation between the 3,5-dinitrophenyl group and the anthracene ring is stronger than that between the naphthyl group and the anthracene ring. On the other hand, polymer type CSPs, such as amylose tris(3,5-dimethylphenylcarbamate), have a large advantage in that enantiomer separation can be obtained without converting chiral lipids into derivatives or into simple derivatives, such as acetates and methyl esters. Thus, the packing materials containing polymer type CSP are useful when derivatization is undesirable or difficult to obtain or when the recovery of each enantiomer is needed.
Generally, compounds having hydroxyl or amino groups can react with isocyanates to form the corresponding urethane or urea derivatives, respectively.

$$
\begin{aligned}
& \mathrm{R}^{1}-\mathrm{OH}+\mathrm{R}^{2}-\mathrm{N}=\mathrm{C}=\mathrm{O} \rightarrow \mathrm{R}^{2}-\mathrm{NHCOO}-\mathrm{R}^{1} \text { (urethane) } \\
& \mathrm{R}^{1}-\mathrm{NH}_{2}+\mathrm{R}^{2}-\mathrm{N}=\mathrm{C}=\mathrm{O} \rightarrow \mathrm{R}^{2}-\mathrm{NHCONH}-\mathrm{R}^{1} \text { (urea) }
\end{aligned}
$$

The 3,5-dinitrophenyl isocyanate and 1- and 2-anthryl isocyanates react readily with glycerolipids having hydroxyl or amino groups, such as PtdGro and PtdSer, at room temperature in toluene in the presence of a base (pyridine or triethylamine). The derivatization not only enables separation of enantiomers but also facilitates detection. For example, the bis(3,5-DNPU) derivatives of monoacylglycerols have a strong absorption at $226 \mathrm{~nm}(\lambda \max )$, as indicated by the $\varepsilon$ value of $c a$. 60,000 in ethanol, and have a good absorption at $254 \mathrm{~nm}(\varepsilon 31,000)$ [5]. Isocyanates are moisture sensitive and therefore, long-term storage is not desirable. Although 3,5-dinitrophenyl isocyanate is commercially available, it can be easily synthesized in the laboratory by thermal decomposition of 3,5-dinitrobenzoyl azide, which is prepared from 3,5dinitrobenzoyl chloride and sodium azide [20]. The 3,5dinitrobenzoyl azide is stable for storage and loses nitrogen at approximately $120^{\circ} \mathrm{C}$ to yield 3,5-dinitrophenyl isocyanate [20]. We have found that 3,5-dinitrophenyl isocyanate and 1(2)-anthryl isocyanate can be easily synthesized by the reactions of 3,5dinitroaniline and 1(2)-aminoanthracene, respectively, with triphosgene [bis(trichloromethyl) carbonate] as a phosgene substitute $[13,17,18]$. Triphosgene is a stable solid, which is safer and more convenient to transport and store than phosgene and diphosgene [21].

\subsection{Enantiomeric mono-, di- and triacylglycerols}

Enantiomeric 1- and 3-monoacyl-sn-glycerols were the first chiral glycerolipids resolved by chiral-phase HPLC [5]. Synthetic racemates with $\mathrm{C} 12-\mathrm{C} 18$ saturated acyl groups in the molecules were converted into the bis(3,5-DNPU) derivatives and then separated into enantiomers on CSP prepared by Oi and Kitahara [23] from acylated amino acid and chiral 2-(4-chlorophenyl)isovaleric acid bonded chemically to silica through ionic linkage (Sumipax OA-2100). To obtain clear enantiomer resolution, a ternary solvent system, hexane/1,2-dichloroethane/ethanol (40:12:3, by vol), was used as the mobile phase. Sumichiral OA-4100 [24,25] and YMC A-K03 [26], both of which contained chiral (R)-1-(1-naphthyl) ethylamide groups as a chiral selector, were also used for this purpose. The best resolution was obtained on OA-4100 within $10 \mathrm{~min}$ on a $25 \mathrm{~cm}$-long column. This OA-4100 column showed an earlier elution of the $s n$-1-enantiomer than the $s n$-3-enantiomer using the same solvent system as that used for OA-2100. However, the sn-2regioisomer almost overlapped with the $s n$-1-enantiomer on the column. Therefore, if the $s n$-2-regioisomer exists in samples, a pre- 
liminary separation of the $s n$-2-isomer from the $s n-1(3)$ enantiomer on thin-layer chromatography (TLC) or achiral-phase HPLC is necessary before enantiomer separation on OA-4100. Although the enantiomer resolutions on OA-2100 $(\alpha=1.18-1.19)$ and A-K $03(\alpha=1.12)$ are poorer than that on OA-4100 ( $\alpha=1.31-$ $1.35)$, the $s n$-2-isomer can be completely resolved with a faster elution than the $s n$-1-enantiomer on OA-2100 $(\alpha=1.28)$. The elution orders of the $s n-1$ - and $s n-3$-enantiomers on OA-4100 and A-K03 are reversed on OA-4100 R and A-L03, respectively, which have opposite configurations. Chiral-phase HPLC of enantiomeric monoacylglycerols has been utilized for the determination of fatty acid positional distribution in triacylglycerol molecules (called stereospecific analysis of triacylglycerols) $[7,9,10]$.

Deng et al. reported direct HPLC separation of enantiomeric and regioisomeric monoacylglycerols on cellulose tris(4chlorophenylcarbamate) (Chiralcel OF) and by using hexane/2propanol eluent mixtures [27]. Without previous derivatization of the samples, García et al. also reported a similar separation of enantiomeric and regioisomeric monoacylglycerols on other polymer type CSPs, namely amylose tris(3,5-dimethylphenylcarbamate) (Chiralpak IA) and cellulose tris(3,5-dichlorolphenylcarbamate) (Chiralpak IC), using hexane/2-propanol eluent mixtures [28]. We have observed that much better separation of both enantiomers and molecular species can be obtained by chiral reversed-phase HPLC on Chiralpak IA and Chiralpak IC by using acetonitrile containing $10-30 \%$ methanol as the mobile phase (Figure 3) [29].

A chiral-phase HPLC resolution of enantiomeric 1,2- and 2,3diacyl-sn-glycerols is also based on the conversion of diacylglycerols into the 3,5-DNPU derivatives by reaction with 3,5dinitrophenyl isocyanate $[22,30]$ and the best separation has been achieved on a column containing bonded ( $R$ )-1-(1-naphthyl)ethylmethacrylamide polymeric phase (YMC A-K03) [26]. Figure 4

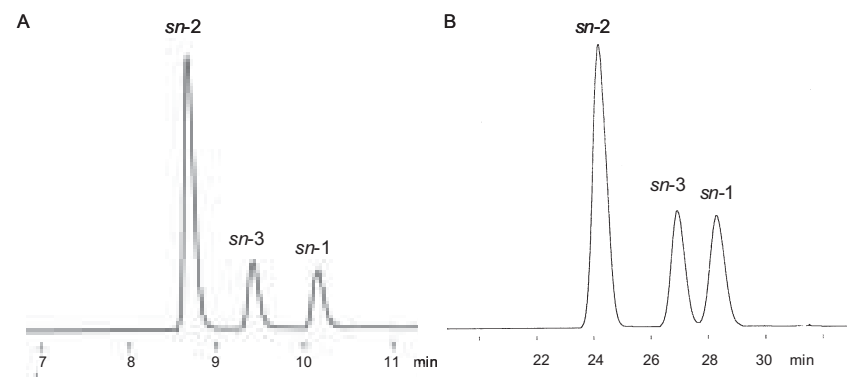

Figure 3. Direct resolution of enantiomeric ( $s n-1$ and $s n-3)$ and regioisomeric ( $s n-2)$ monoarachidonoylglycerols (20:4) by chiral-phase HPLC on amylose tris(3,5-dimethylphenylcarbamate). Column: Chiralpak IA ( 250 x $4.6 \mathrm{~mm}$ ID, 5 $\mu \mathrm{m}$ particles). Mobile phase: (A) $\mathrm{CH}_{3} \mathrm{CN} / \mathrm{MeOH}$ (90:10, by vol); (B) hexane/MeOH (96:4, by vol); Flow rate: 0.5 $\mathrm{mL} / \mathrm{min}$. Column temperature: (A) $20^{\circ} \mathrm{C}$; (B) $25^{\circ} \mathrm{C}$. Detection: $\operatorname{ELSD}\left(50^{\circ} \mathrm{C}\right)$.
A
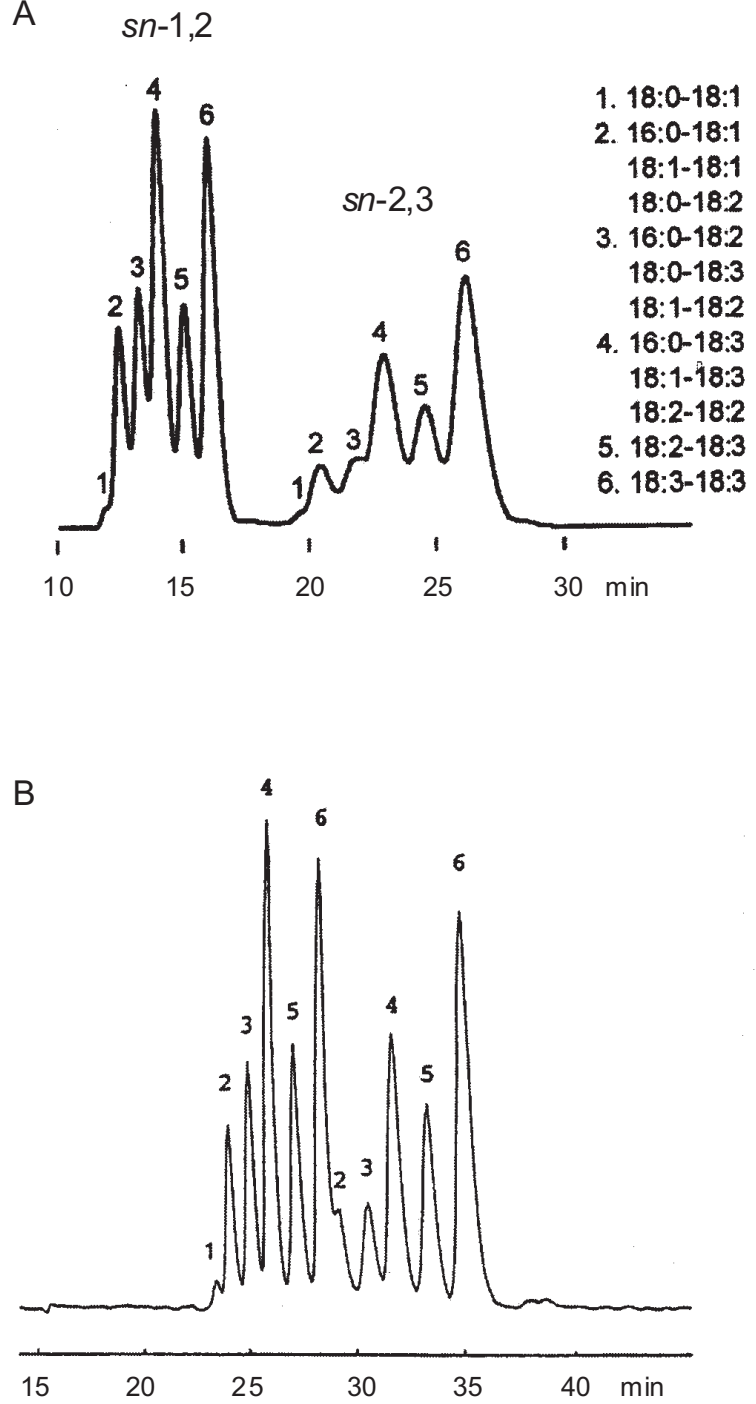

Figure 4. Chiral-phase HPLC profiles of the 3,5-dinitrophenylurethane derivatives of 1,2- and 2,3-diacyl-sn-glycerols derived from linseed oil triacylglycerols on a column containing $(R)$-1-(1-naphthyl)ethylmethacrylamide polymer (A-K03, $250 \times 4.6 \mathrm{~mm}$ ID). Column temperature: (A) $10^{\circ} \mathrm{C}$; (B) $28^{\circ} \mathrm{C}$. Mobile phase: hexane $/ \mathrm{CH}_{2} \mathrm{Cl}_{2} /$ EtOH (40:10:1, by vol). Flow rate: (A) $1 \mathrm{~mL} / \mathrm{min}$; (B) $0.5 \mathrm{~mL} / \mathrm{min}$. Detection: $254 \mathrm{~nm}$. From [13].

shows the HPLC chromatograms of the 3,5-DNPU derivatives of the 1,2- and 2,3-diacyl-sn-glycerol moieties of linseed oil triacylglycerols at different column temperatures. The derivatives were resolved by an isocratic elution with hexane/1,2-dichloroethane/ ethanol (40:10:1, by vol) as the mobile phase, with the $s n-1,2-$ enantiomers emerging ahead of the $s n-2,3$-enantiomers. Typically, for such CSP, the magnitude of the separation factors for enantiomeric pairs increases as the column temperature of the CSP is reduced [19]. In fact, better separation of enantiomeric diacylglycerols was achieved at lower temperatures (Figure 4A). Thus, analysis 
at lower temperatures is especially effective for the separation of an enantiomer mixture consisting of many molecular species with saturated and unsaturated acyl groups, which are partially resolved on CSP according to their equivalent carbon numbers $(\mathrm{ECN}=$ total number of carbon atoms in the two constituent fatty acids $-2 \mathrm{x}$ total number of their double bonds) [26]. Thermodynamic consideration for enantiomer separation of diacylglycerols on CSP has been described elsewhere $[13,31]$. The chiral-phase HPLC method described here has been extensively utilized in stereospecific analyses of diacylglycerol moieties derived from natural triacylglycerols by random degradation with Grignard reagent [32-36].

We utilized chiral-phase HPLC for the determination of the stereochemical configuration of glycerol moieties in glycoglycerolipids [37]. For this purpose di- and monoacylglycerols were released from glycosyldi- and glycosylmonoacylglycerols (see Figure $1 \mathrm{H}$ ), respectively, by periodate oxidation followed by hydrazinolysis. The released di- and monoacylglycerols were converted into 3,5-DNPU and bis(3,5-DNPU) derivatives, respectively, as described above. The derivatives were separated on two CSP of opposite configuration, $(R)$ - and (S)-1-(1-naphthyl)ethylmethacrylamide polymers (A-K03 and A-L03) for diacylglycerols and $N$-(R)-(1-naphthyl)ethylaminocarbonyl-( $S$ )-valine (OA-4100) and $N$-(S)-1-(1-naphthyl)ethylaminocarbonyl-( $R$ )-valine (OA-4100 R) for monoacylglycerols. Using the above method, we determined the glycerol configuration in the glycosyldiacylglycerols (monogalactosyl-, digalactosyl-, and sulfoquinovosyldiacylglycerols) and glycosylmonoacylglycerols (monogalactosyl-, digalactosyl -, and sulfoquinovosylmonoacylglycerols) isolated from spinach leaves and the coralline red alga Corallina pilulifera. The results clearly showed that the glycerol moieties in all the glycoglycerolipids examined have $S$-configuration (1,2-diacyl-sn-glycerols and 1monoacyl-sn-glycerols).

We have also developed a highly sensitive method for the separation and detection of enantiomeric and regioisomeric diacylglycerols as 1- and 2-anthrylurethanes by chiral-phase HPLC with fluorescence detection $[17,18]$. The derivatives were obtained by reaction with 1(2)-aminoanthracene and triphosgene in acetonitrile at $100^{\circ} \mathrm{C}$. Again, satisfactory resolution of the enantiomers and regioisomers was achieved on A-K03, using a mixture of hexane/dichloromethane/ethanol (150:10:1, by vol) as the mobile phase (see Figure 2). Under working conditions, the $s n$-1,2-enantiomers eluted ahead of the $s n-2,3$-enantiomers and both were preceded by the X-1,3-regioisomers. Like the 3,5-DNPU, the anthrylurethanes eluted from the columns according to their ECN values. The detection limit of 2-anthrylurethanes was 1 fmol when the signal-tonoise ratio was $3: 1$.

Piyatheerawong et al. [38] have reported an analytical method in which enantiomeric 1,2- and 2,3-diacyl-sn-glycerols can be di- rectly separated without any derivatization. The method is based on a cellulose tris(3,5-dimethylphenylcarbamate) column (Chiralcel OD), which allows for separation of underivatized 1,2- and 2,3diacyl-sn-glycerols, provided a conventional silica gel column is used in tandem to separate 1,3-diacylglycerols from 1,2(2,3)diacylglycerols before they enter the CSP column. There is no need to isolate the fraction of 1,2(2,3)-diacylglycerols in advance. For this purpose, a silica gel column (Ultrasphere, $5 \mu \mathrm{m}$ column, $250 \mathrm{x}$ $4.6 \mathrm{~mm}$ ID) was connected in series with the CSP column $(250 \mathrm{x}$ $4.6 \mathrm{~mm}$ ID). The mobile phase was hexane/2-propanol (300:7, by vol) at a flow rate of $1.0 \mathrm{~mL} / \mathrm{min}$ at $25^{\circ} \mathrm{C}$. An authentic mixture of 1,3-dicapryloyl- and racemic 1,2-dicapryloylglycerols subjected to tandem column HPLC yielded $s n-1,3-, s n-2,3-$, and $s n-1,2$-isomers at 26, 32, and $34 \mathrm{~min}$, respectively. Comparable results were obtained for isomeric mixtures of dioleoylglycerol. The method was used for the evaluation of the stereospecificity of action of immobilized Candida antarctica lipase B and Rhizomucor miehei lipase, which possessed opposite stereospecificity. Although enantiomeric separation without derivatization is convenient, it does not exclude isomerization of diacylglycerols in the free form on silica column HPLC. Free diacylglycerols are known to undergo isomerization even in a solid state [39]. Recently, we have observed that much better resolution of enantiomeric 1,2- and 2,3-diacyl-sn-glycerols and their molecular species as free forms is obtained by chiral reversed-phase HPLC on amylose tris(3,5-dimethylphenylcarbamate) (Chiralpak IA) using acetonitrile/methanol eluent mixtures (Figure 5).

Some asymmetric triacylglycerols with very different acyl groups have been successfully resolved without derivatization by chiral-phase HPLC on polysaccharide-based CSP [40]. Enantiomeric 1-eicosapentaenoyl-2,3-dicapryroyl-sn-glycerol (20:5-8:08:0) and 1,2-dicapryroyl-3-eicosapentaenoyl-sn-glycerol (8:0-8:020:5) were almost completely resolved with a peak resolution $(R s)$ of 1.07 on a cellulose tris(4-chlorophenylcarbamate) column (Chiralcel OF, 250 x 4.6 mm ID) using hexane/2-propanol (100:1, by vol) as the mobile phase. Excellent resolution with an $R s$ value greater than 11 was achieved for enantiomeric 1-docosahexaenoyl2,3-dicapryroyl-sn-glycerol (22:6-8:0-8:0) and 1,2-dicapryroyl-3docosahexaenoyl-sn-glycerol (8:0-8:0-22:6) on a Chiralcel OD column ( 250 x $4.6 \mathrm{~mm}$ ID) using hexane/2-propanol (200:1, by vol) as the mobile phase at $1 \mathrm{~mL} / \mathrm{min}$ and $25^{\circ} \mathrm{C}$. Recently, Nagai et al. employed recycle HPLC for the separation of enantiomeric triacylglycerols possessing minor differences in chain lengths and degrees of unsaturation [41]. Effective enantiomer separation was obtained in $150 \mathrm{~min}$ for 1,2-dipamitoyl-3-oleoyl-rac-glycerol (16:0-16:0-18: 1), 1,2-dioleoyl-3-palmitoyl-rac-glycerol (18:1-18:1-16:0), and 1,2 -dipalmitoyl-3-linoleoyl-rac-glycerol (16:0-16:0-18:2) on a Chiralcel OD-RH column (150 x $4.6 \mathrm{~mm}$ ID, $5 \mu \mathrm{m}$ particles $)$ using 


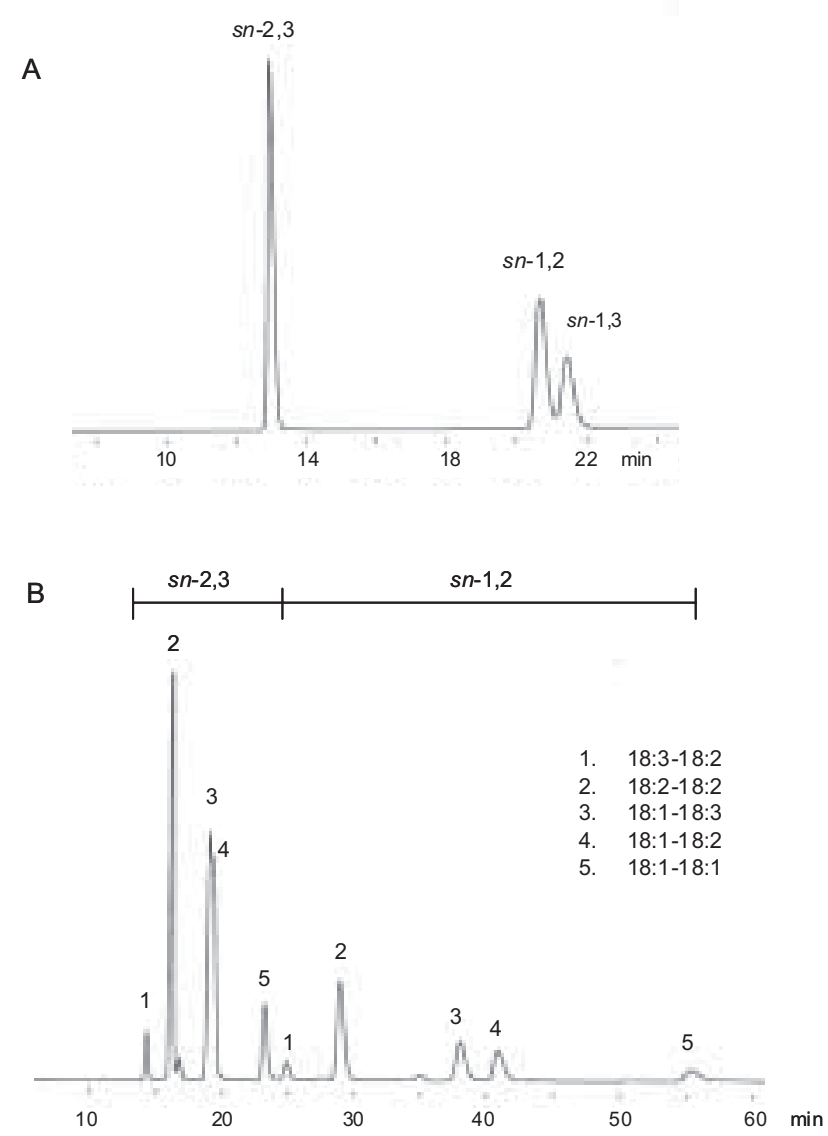

Figure 5. Direct resolution of isomeric diacylglycerols by chiral reversed-phase HPLC on amylose tris(3,5-dimethylphenylcarbamate). (A) a mixture of enantiomeric ( $s n$ $1,2$ and $s n-2,3)$ and regioisomeric $(s n-1,3)$ dilinoleoylglycerols (18:2-18:2) ; (B) a mixture of enantiomeric 1,2 - and 2,3-diacyl-sn-glycerols having various pairs of acyl groups. Column: Chiralpak IA ( 250 x $4.6 \mathrm{~mm} \mathrm{ID,} 5$ $\mu \mathrm{m}$ particles). Mobile phase: $\mathrm{CH}_{3} \mathrm{CN} / \mathrm{MeOH}$ (90:10, by vol); Flow rate: $0.5 \mathrm{~mL} / \mathrm{min}$. Column temperature: (A) $25^{\circ} \mathrm{C}$; (B) $15^{\circ} \mathrm{C}$. Detection: ELSD $\left(50^{\circ} \mathrm{C}\right)$.

methanol as the mobile phase $\left(0.5 \mathrm{~mL} / \mathrm{min}\right.$ at $\left.25^{\circ} \mathrm{C}\right)$, but neither 1,2-dioleoyl-3-linoleoyl-rac-glycerol (18:1-18:1-18:2) nor 1,2dipalmitoyl-3-stearoyl-rac-glycerol (16:0-16:0-18:1) was resolved. These techniques used are simple and useful for the determination of enantiomeric purity of synthetically structured lipids and some natural triacylglycerols.

For enantiomer separation of glycerolipids, columns of 150$250 \mathrm{~mm}$ length and $4-4.6 \mathrm{~mm}$ inside diameter are usually used. Separation can be further improved by using the same two or three columns connected in series $[22,25]$. Capillary columns packed with OA-2100 (300 x $0.32 \mathrm{~mm}$ ID) have also been used for enantiomer resolution of racemic 1-alkylglycerols (glyceryl ethers), $\alpha$ hydroxy acids and 1,2-alkanediols [42-44]. We believe that future popularization of chiral-phase HPLC using capillary columns can be expected since it is effective in HPLC in conjunction with mass spectrometry (HPLC/MS) and does not need expensive chiral materials and toxic mobile phases. Hexane and dichloromethane (or 1,2-dichloroethane), which have frequently been used in chiralphase HPLC, are now considered neurotoxic and carcinogenic, respectively.

Natural glycerolipids consist of various molecular species differing in polarity, which may be exploited by both normal- and reversed-phase chromatography. The glycerolipids with shorter chain lengths and higher degrees of unsaturation are more polar than those with longer and more saturated chains. In normal-phase chromatography, the less polar compounds are eluted ahead of the more polar ones, while during reversed-phase chromatography the more polar ones are eluted ahead of the less polar ones. During chiral-phase HPLC, we found that the glycerolipids were subject to both polar and non-polar interactions with CSP, in addition to chiral interaction [5]. Thus, chiral-phase HPLC gives complex chromatograms for natural glycerolipids (see Figure 4). Complete separation of individual molecular species in both enantiomers can be obtained when polar capillary gas chromatography [45] or reversed-phase HPLC [13] is used jointly with chiral-phase HPLC. Reversed-phase HPLC/ESI-MS provides both sensitive detection and identification of the solutes $[33,46]$.

\subsection{Diastereomeric glycerophospholipids}

Glycerophospholipids are similar to triacylglycerols in that it is difficult to achieve clear HPLC resolution of stereoisomers in appropriate elution times. One of the reasons is that phospholipids do not have the suitable functional groups for derivatization used in stereoisomer separation by chiral-phase HPLC. However, some phospholipids with hydroxyl or amino groups, such as lysoPtdCho, PtdGro, and PtdSer, react easily with 3,5-dinitrophenyl isocyanate to form the corresponding urethane or urea derivatives, respectively, which are separable on chiral-phase HPLC. For the first time, we used chiral-phase HPLC for the resolution of enantiomeric and diastereomeric glycerophospholipids during a reassessment of the stereochemical configuration of natural PtdGro molecules [47]. For this purpose, synthetic and natural PtdGro samples were converted to their bis(3,5-DNPU) derivatives, which were confirmed by electrospray ionizarion (ESI)-MS and then separated by HPLC using two columns having chiral phases of opposite configuration, $(R)$ - and $(S)$-1-(1-naphthyl)ethylmethacrylamide polymers (YMC A-K03 and A-L03). Figure 6 shows chiral-phase HPLC profiles of some synthetic and natural PtdGro as bis(3,5DNPU) derivatives. Absolute configurations of the resolved peaks were assigned by comparison with the elution order of the corresponding 1- and 3-monoacyl-sn-glycerol enantiomers as bis(3,5DNPU) derivatives on the same column. We employed this method 
A
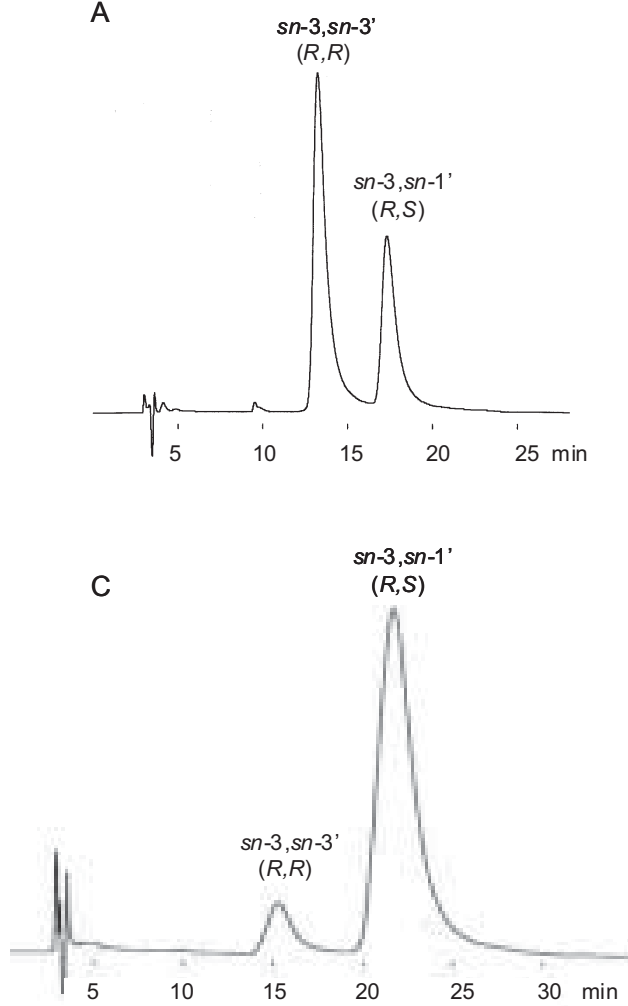
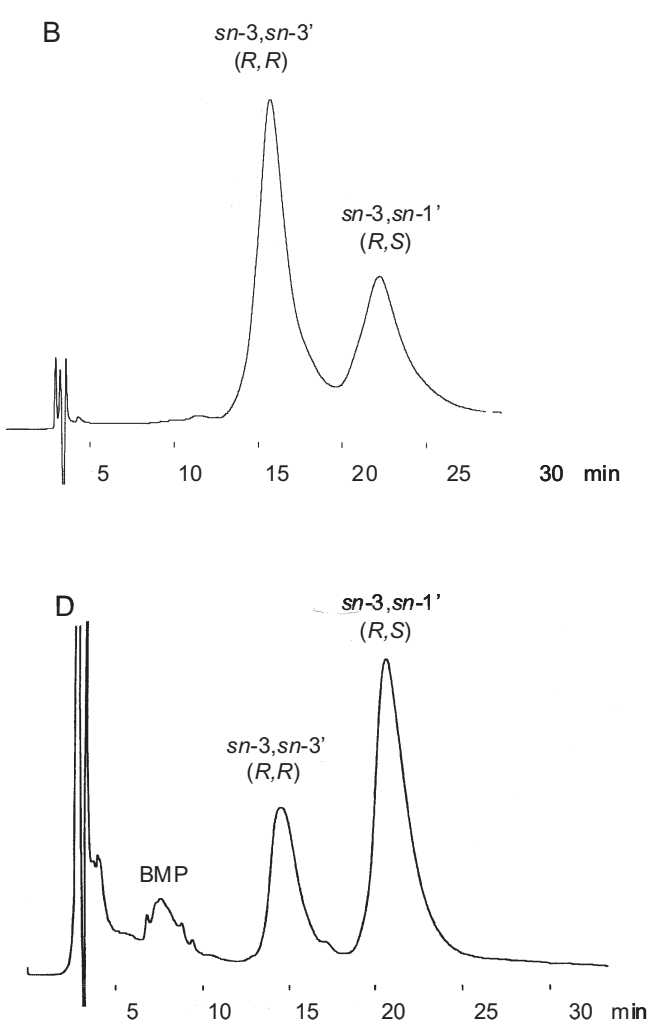

Figure 6. Chiral-phase HPLC profiles of the bis(3,5-dinitrophenylurethane) derivatives of synthetic and natural phosphatidylglycerols (PtdGro). Upper panel: Synthetic PtdGro generated from 1,2-dioleoyl-sn-glycero-3-phosphocholine (A) or salmon roe phosphatidylcholines (B) and glycerol by transphosphatidylation with phospholipase D from Streptomyces septatus TH-2; Lower panel: PtdGro from Escherichia coli (C) and rat lung (D). sn-3, sn-1': 1,2-diacyl-sn-glycero-3-phospho-1'-sn-glycerol ( $R, S$ configuration) ; $s n$-3, sn-3': 1,2-diacyl-sn-glycero-3-phospho-3'-sn-glycerol ( $R, R$ configuration); BMP: bis(monoacylglycerol) phosphate. Column: YMC A-K03 (250 x $4.6 \mathrm{~mm}$ ID, $5 \mu \mathrm{m}$ particles). Mobile phase: hexane $/ \mathrm{CH}_{2} \mathrm{Cl}_{2} / \mathrm{MeOH} / \mathrm{TFA}$ (60:20:20:0.2, by vol, $1 \mathrm{~mL} /$ min). Column temperature: $10^{\circ} \mathrm{C}$. Detection: $254 \mathrm{~nm} \mathrm{UV}$.

for the determination of the stereochemical configuration of PtdGro prepared by phospholipase D-catalyzed transphosphatidylation from PtdCho and glycerol [48]. All chromatograms obtained for bacterial phospholipase D products showed two clearly resolved peaks of different proportions of diastereomers ranging from 30$40 \%$ 1,2-diacyl-sn-glycero-3-phospho-1'-sn-glycerol $(R, S$ configuration) and 60-70\% 1,2-diacyl-sn-glycer-3-phospho-3'-sn-glycerol $(R, R$ configuration). (Figure $6 \mathrm{~A}, 6 \mathrm{~B})$. The asymmetric proportions were absent from the diastereomers prepared with cabbage or peanut phospholipase $\mathrm{D}$, which gave equimolar mixtures of $R, S$ and $R, R$ diastereomers. It was concluded that bacterial phospholipase $\mathrm{D}$ catalyzed transphosphatidylation proceeds to a large extent stereospecifically, showing a preference for the $s n-3$ '-position of the glycerol molecule. We used this method to demonstrate a marked effect of temperature on the stereoselectivity of phospholipase D toward the two primary hydroxyl groups of glycerol in the transphosphatidylation reaction of PtdCho to PtdGro [49]. The proportion of the $R, R$ isomer produced with phospholipase D from Streptomyces TH-2 and Actinomadura sp. changed gradually from
$50 \% R, R$ and $50 \% R, S$ at $50-60{ }^{\circ} \mathrm{C}$ to $70 \% R, R$ and $30 \% R, S$ at 0 ${ }^{\circ} \mathrm{C}$. Based on these studies, we developed a simple method for synthesizing diastereomerically pure $R, R$ and $R, S$ PtdGro molecules [50]. For this purpose, 1,2- $O$-isopropylidene PtdGro diastereomers were prepared from 1,2-diacyl-sn-glycero-3-phosphocholine (PtdCho) and enantiomeric 1,2-O - and 2,3-O-isopropylidene-snglycerols [51] by transphosphatidylation with phospholipase D from Actinomadura in acetate buffered diethyl ether at $30^{\circ} \mathrm{C}$. The isopropylidene protective group was removed by heating the isopropylidene PtdGro diastereomers at $100^{\circ} \mathrm{C}$ in trimethylborate in the presence of boric acid [49]. Using the method, we have found that some bacterial $[47,52,53]$ and mammalian PtdGro molecules contain a significant amount of $R, R$ isomer, of which existence had not been previously reported (Figure 6C, 6D). We have also found that the $R, R$ isomer in bacteria increased gradually with increasing growth temperature, suggesting adaptation toward environmental change [54]. These studies demonstrated that chiralphase HPLC and ESI-MS provided direct and unambiguous information about the configuration, identity, and quantity of molecular 
A

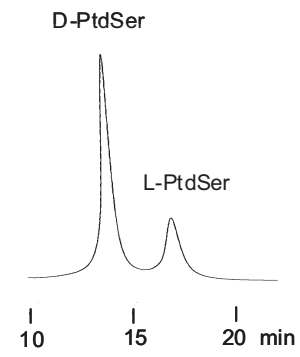

C

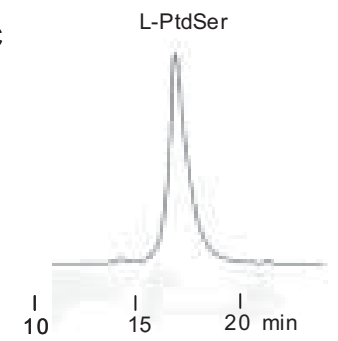

E

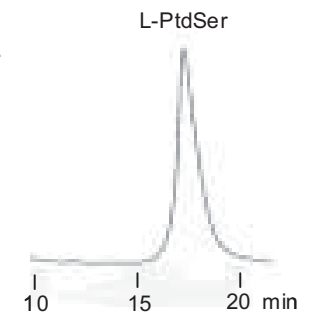

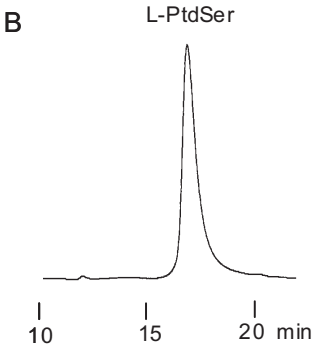
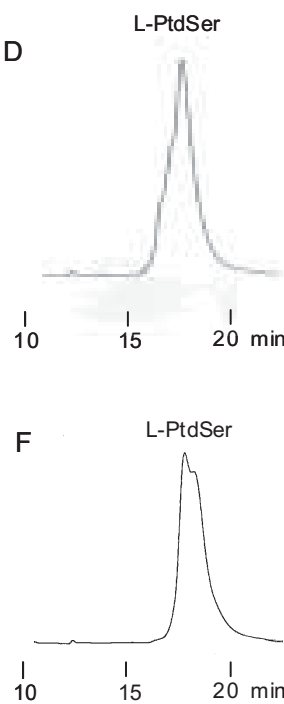

Figure 7. Chiral-phase HPLC profiles of synthetic and natural phosphatidylserines (PtdSer) as 3,5-dinitrophenylurea derivatives on polymeric $(R)$-1-(1-naphthyl)ethylmethacrylamide. (A) a mixture of synthetic $\mathrm{L}$ - and D-PtdSer; (B) synthetic L-PtdSer; (C) rat brain; (D) mackerel eye; (E) rat liver; (F) mackerel liver. Column: YMC A-K03 ( $250 \times 4.6 \mathrm{~mm}$ ID, $5 \mu \mathrm{m}$ particles). Mobile phase: hexane/ $\mathrm{CH}_{2} \mathrm{Cl}_{2} / \mathrm{MeOH} / \mathrm{TFA}$ (70:20:10:0.2, by vol, $1 \mathrm{~mL} /$ min). Column temperature: $10^{\circ} \mathrm{C}$. Detection: $254 \mathrm{~nm}$ UV.

species in natural and synthetic PtdGro.

We have also reported the chiral-phase resolution of diastereomeric phosphatidyl-D-serine and L-serine following derivatization with 3,5-dinitrophenyl isocyanate and purification by normal-phase HPLC on a polyvinyl alcohol bonded silica column (YMC PVA-SIL, 100 x 3 mm ID) [14,55]. Complete resolution of diastereomeric L-PtdSer and D-PtdSer was achieved by HPLC on two CSP of opposite configuration, $(R)$ - and (S)-1-(1-naphthy) ethylmethacrylamide polymers (YMC A-K03 and A-L03 columns, each 250 x $4.6 \mathrm{~mm}$ ID), using hexane/dichloromethane/methanol/ trifluoroacetic acid (70:20:10:0.2, by vol) as the mobile phase. The diastereomers eluted with a reversal in the elution order on the two columns. Using this method, we have demonstrated that the serine moiety of the PtdSer isolated from rat brain, rat liver, mackerel eye, and mackerel liver only had the L-configuration (Figure 7), al- though approximately $1 \%$ of total PtdSer was detected in rat cerebrum by reversed-phase HPLC of the fluorescent derivatives of serine liberated from PtdSer by hydrolysis [56].

\subsection{Enantiomeric ether lipids}

Glycerolipids with ether linkages are widely distributed in nature from microorganisms to animals, especially in the liver oil of deep-sea sharks. It is known that the ether linkage of the glycerolipids from animals is located at the $s n-1$ position in the glycerol skeleton, but is at the $s n-3$ position in the phospholipids of archaebacterium [57]. In platelet activating factor (PAF, 1-alkyl-2-acetyl$s n$-glycero-3-phosphocholine), the ether linkage at the $s n-1$ position is essential for expression of activity [58]. The position of an ether linkage in glycerolipids can be determined by chiral-phase HPLC. The acyl and/or phosphate groups of ether lipids are hydrolyzed to generate monoalkylglycerols (glyceryl ethers). These are then converted into the bis(3,5-DNPU) derivatives for chiral-phase HPLC and on-line ESI-MS. Each isomer of 1-, 2-, and 3-alkyl-snglycerols is clearly separated on Sumichiral OA columns [59-61]. The HPLC chromatograms and HPLC/ESI-MS spectra of the monoalkylglycerols derived from diacylalkylglycerols in the liver oil of the megamouth shark Megachasma pelagios [60] and in the muscle lipids from a deep-sea teleost fish Stromateus stellatus [61] showed no peaks that correspond to $s n$-2- and $s n$-3-isomers, demonstrating that the ether linkage occurs only at the $s n-1$ position of the glycerol backbone. The enantiomers of alkylacylglycerols and dialkylglycerols have also been well separated on OA-4100 [62] after conversion into their 3,5-DNPU derivatives.

\subsection{Enantiomeric lysophosphatidylcholines (lyso-PtdCho)}

We have investigated the chiral-phase HPLC resolution of intact lyso-PtdCho (Figure 8) [63]. Lyso-PtdCho is an abundant com-
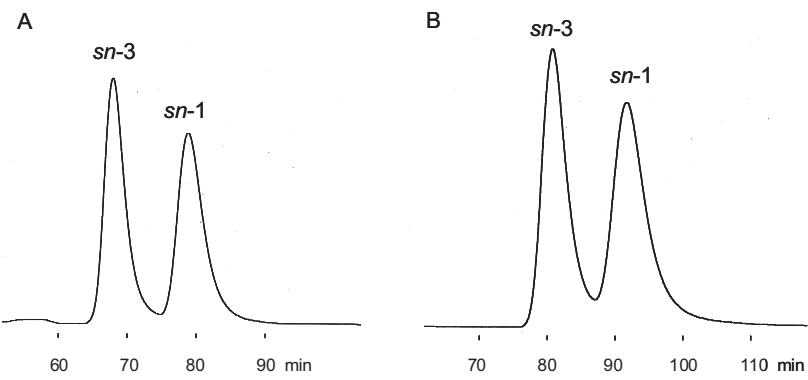

Figure 8. Chiral-phase HPLC resolution of the 3,5-dinitrophenylurethane derivatives of (A) 1-palmitoyl-rac-glycero-3phosphocholine (2-lyso-PtdCho) and (B) 1-hexadecylrac-glycero-3-phosphocholine (lyso-PAF). Column: two Chiralcel OD-RH columns (each 150 x $4.6 \mathrm{~mm}$ ID, $5 \mu \mathrm{m}$ particles) in series; Mobile phase: $\mathrm{MeOH} / \mathrm{H}_{2} \mathrm{O}$ (90:10, by vol) at $0.25 \mathrm{~mL} / \mathrm{min}$; Column temperature: $5^{\circ} \mathrm{C}$; Detection: $254 \mathrm{~nm} \mathrm{UV}$. 
ponent of plasma and oxidized low-density lipoprotein (LDL) that displays several biological activities, some of which may occur through the PAF receptor [64]. Near baseline resolution of enantiomeric 2-lyso-PtdCho (1-acyl-2-hydroxy-sn-glycero-3-phosphocholine and 3-acyl-2-hydroxy-sn-1-glycero-1-phosphocholine) as 3,5-DNPU has been achieved on a CSP column of the reversedphase type (Chiralcel OD-RH) (Figure 8A). A good separation was also achieved for its alkyl homolog (lyso-PAF) (Figure 8B). The analysis was conducted at $5^{\circ} \mathrm{C}$ on two columns connected in series (each $150 \mathrm{~mm} \times 4.6 \mathrm{~mm}$ ID) using a simple solvent system with methanol/water $(90: 10, v / v)$ as the mobile phase. Under the same conditions, partial separation can be obtained for enantiomeric 1(3) -lyso-PtdCho (1-hydroxy-2-acyl-sn-glycero-3-phosphocholine and 3-hydroxy-2-acyl-sn-glycero-1-phosphocholine) as 3,5-DNPU (chromatograms not shown).

\subsection{Enantiomeric glycidol fatty acid esters (GE)}

Finally, we have investigated the determination of 2,3-epoxy1-propanol (glycidol) fatty acid esters, which are undesirable contaminants formed mainly during the refining processes of edible

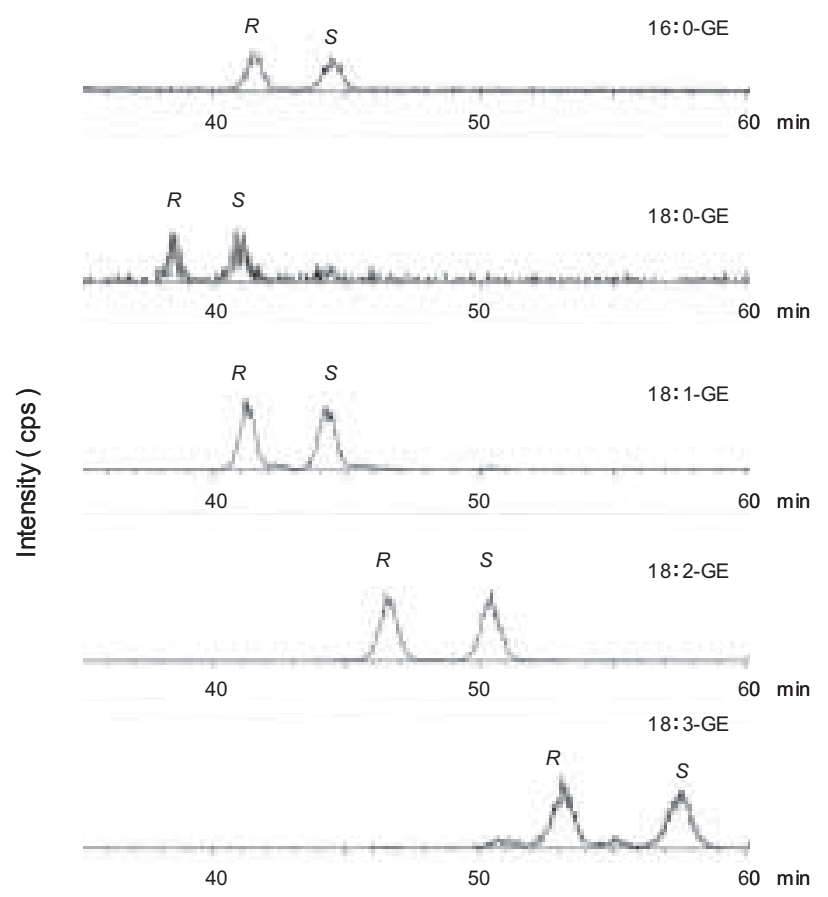

Figure 9. A column-switching HPLC/APCI-MS profiles of the glycidol fatty acid esters in a diacylglycerol-rich oil. 1 st column: silica ( $250 \times 4.6 \mathrm{~mm}$ ID, $5 \mu \mathrm{m}$ particles); 2 nd column: Chiralpak IC (250 x $4.6 \mathrm{~mm}$ ID); Mobile phase: isocratic elution with hexane/2-propanol, 99.5: 0.5 , by vol) at $5^{\circ} \mathrm{C}(1 \mathrm{st}$ column $)$ and $20^{\circ} \mathrm{C}$ (2nd column). MS: API 2000 Q Trap MS/MS. Scan mode: MRM (precursor ion, $[\mathrm{M}+\mathrm{H}]^{+}$). Injection volume: 20 $\mu \mathrm{L}(30 \mathrm{mg} / \mathrm{mL}$ hexane). oils and have a high health risk potential because of the epoxy ring structure. Free glycidol, which may be released from GE during the digestive process by lipase-catalyzed reactions, is classified as possibly carcinogenic [65]. The detection and quantification of GE molecules in refined edible oils have been carried out using HPLCMS or GC-MS [66]. Although GE has enantiomers (see Figure 1 J), no studies have been carried out for their enantiomer resolution and composition in refined edible oils. Using chiral normal-phase or chiral reversed-phase HPLC in conjunction with atmospheric pressure chemical ionization (APCI)-MS on Chiralpak IA, we have demonstrated that the GE molecules in some refined edible oils are composed of approximately equal amounts of $R$ and $S$ enantiomers (Figure 9). A column-switching HPLC/APCI-MS method was developed for this purpose [67]. In the case of chiral normal-phase HPLC, an edible diacylglycerol-rich oil $(0.6 \mathrm{mg})$ dissolved in hexane was injected into a silica column (250 x $4.6 \mathrm{~mm}$ ID) and GE was fractionated as a mixture of palmitate (16:0-GE), stearate (18:0 -GE), oleate (18:1-GE), linoleate (18:2-GE), and linolenate (18:3GE). The GE mixture was introduced to the analytical column (Chiralpak IC, $250 \times 4 \mathrm{~mm}$ ID, $5 \mu \mathrm{m}$ particles) and individual GE molecules were separated and detected by on-line APCI-MS. The HPLC analyses on silica and chiral columns were done under isocratic elutions with hexane/2-propanol (99.5:0.5, by vol). Postcolumn addition of ethanol was used to assure APCI in the positive mode [61]. Quantification was successfully performed in multiple reaction monitoring $(\mathrm{MRM})$ mode using a precursor ion $[\mathrm{M}+\mathrm{H}]^{+}$. The contents of 16:0-GE, 18:0-GE, 18:1-GE, 18:2-GE, and 18:3GE were $6.6,2.6,74,118$, and $49 \mu \mathrm{g} / \mathrm{g}$, respectively. The total amount of GE $(250 \mu \mathrm{g} / \mathrm{g})$ was less than that reported previously by Masukawa et al. $(295 \mu \mathrm{g} / \mathrm{g})$, where a combination of double SPE and reversed-phase HPLC/MS was used [66]. The columnswitching HPLC/MS method is simple and rapid and can be utilized for the identification and quantification of GE mixtures in various refined edible oils. Synthetic racemates of fatty acid monoand diesters of 3-chloro-1,2-propanediol, which is a glycidol related substance, can also be clearly resolved into enantiomers by both chiral normal-phase HPLC and chiral reversed-phase HPLC on Chiralpak IA columns ( 250 x $4.6 \mathrm{~mm}$ ID, $5 \mu \mathrm{m}$ particles) (chromatograms not shown).

\section{Reversed-phase HPLC of regioisomeric glycerolipids}

\subsection{Diacylglycerol reverse isomers}

The 3,5-DNPU derivatives are suitable for the resolution of regioisomers (reverse isomers) within an enantiomeric class of diacylglycerols ( $s n-1,2-$ or $s n-2,3-)$, as well as for the resolution of enantiomers. The UV absorbing derivatives are readily detected by a spectrophotometer or by a mass spectrometer. The reverse isomers of diacylglycerols (see Figure 1 C, 1 D) having various pairs 

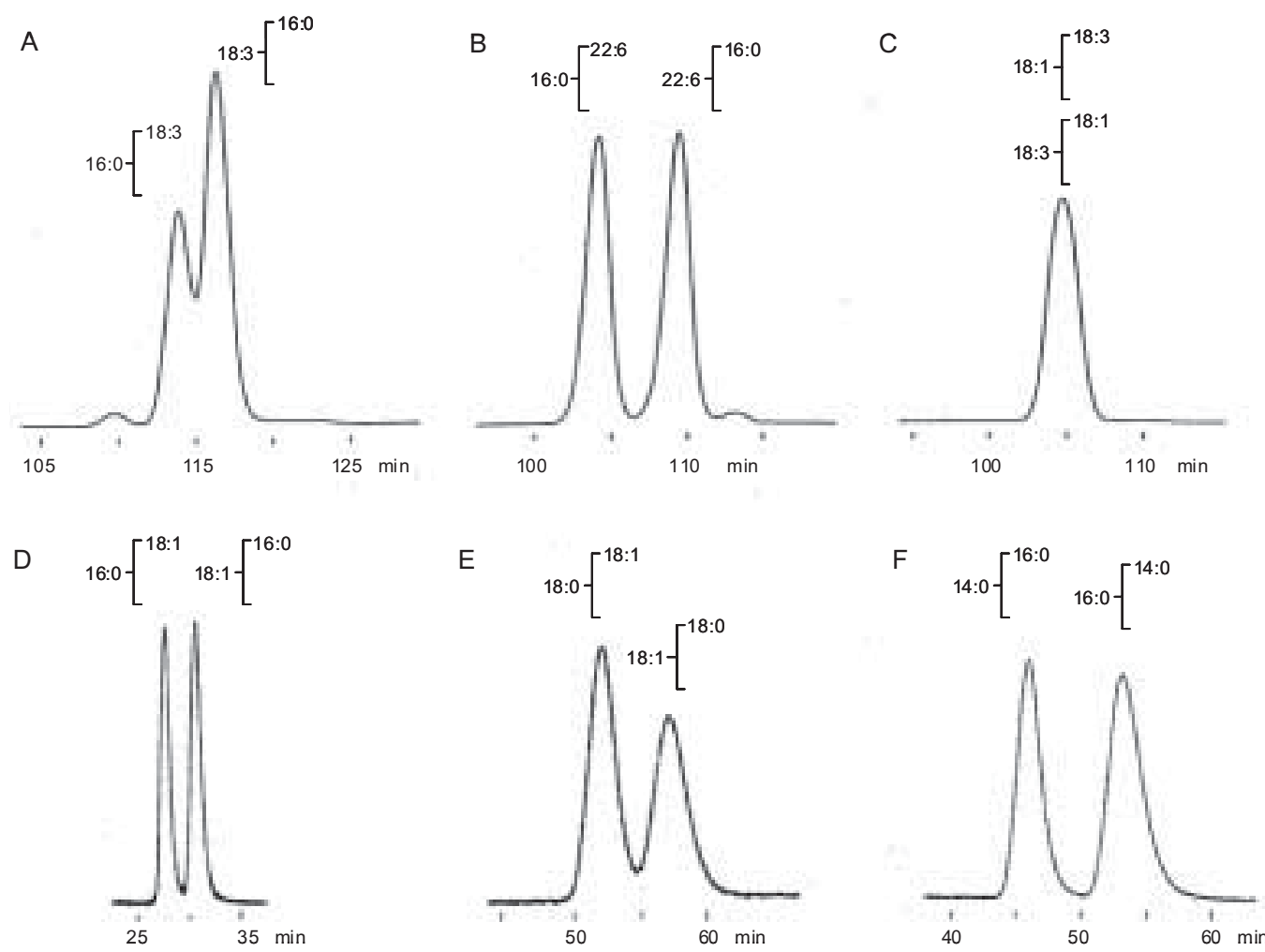

Figure 10. Reversed-phase HPLC resolution of the reverse isomers of 1,2-diacyl-rac-glycerols as 3,5-dinitrophenylurethanes. Peak identification: (A) 1-linolenoyl-2-palmitoyl-rac-glycerol and 1-palmitoyl-2-linolenoyl-rac-glycerol; (B) 1-docosahexaenoyl-2-palmitoylrac-glycerol and 1-palmitoyl-2-docosahexaenoyl-rac-glycerol; (C) 1-linolenoyl-2-oleoyl-rac-glycerol and 1-oleoyl-2-linolenoyl$r a c$-glycerol; (D) 1-oleoyl-2-palmitoyl-rac-glycerol and 1-palmitoyl-2-oleoyl-rac-glycerol; (E) 1-oleoyl-2-stearoyl-rac-glycerol and 1-stearoyl-2-oleoyl-rac-glycerol; (F) 1-palmitoyl-2-myristoyl-rac-glycerol and 1-myristoyl-2-palmitoyl-rac-glycerol. Column: (upper panel) a fully endcapped ODS, Superspher RP-18e $\left(250 \times 4 \mathrm{~mm} \mathrm{ID,} 4 \mu \mathrm{m}\right.$ particles) and isocratic elution with $\mathrm{CH}_{3}$ $\mathrm{CN}$ at $18^{\circ} \mathrm{C}$; (lower panel) a polymeric non-endcapped ODS, Zorbax Eclipse PAH C18 (150 x $4.6 \mathrm{~mm}$ ID, $3.5 \mu \mathrm{m}$ particles) and isocratic elution with $\mathrm{MeOH}$ at $30^{\circ} \mathrm{C}$. Detection: $254 \mathrm{~nm} \mathrm{UV}$.

of acyl groups, including saturated and highly unsaturated chains, when chromatographed as the 3,5-DNPU derivatives, give excellent separations on highly efficient and fully endcapped ODS columns (Figure 10B) and on silver loaded cation-exchange columns [6]. No satisfactory resolution by any of the HPLC methods, however, was obtained for the reverse isomers possessing only minor differences in chain lengths and degrees of unsaturation, such as palmitate/linolenate (16:0/18:3) and oleate/linolenate (18:1/18:3) (Figure 10A, 10C). Recently, we have found that these critical pairs of reverse isomers can be resolved clearly on non-endcapped polymeric ODS columns, as shown in Figure 10D-10F. The highly dense packing of octadecyl groups in polymeric ODS and the planar structure of the 3,5-DNPU moiety in the derivatives would contribute to such reverse isomer separation. The derivatives with various pairs of acyl groups could deeply penetrate the narrow space between polymeric ODS groups and interact more strongly with polymeric ODS than with monomeric ODS. Thus, the reverse isomers having minor differences in chain lengths and degrees of unsaturation would be clearly resolved on polymeric ODS. The re- verse isomers of very different pairs of acyl groups are clearly resolved on both endcapped and non-endcapped monomeric ODS columns, which retain less polar isomers longer with lower degrees of unsaturation or shorter chain lengths at the $s n-1(3)$ position. The non-endcapped columns, however, markedly shorten the elution times of the derivatives compared to the endcapped columns [68]. Most commercially available ODS columns are fully endcapped to decrease undesirable influence of residual silanol. Our study, however, demonstrates that non-endcapped ODS phases are more suitable for the separation of diacylglycerol reverse isomers than fully endcapped ones.

We have utilized the reversed-phase HPLC method of resolution of reverse isomers of diacylglycerols in a chromatographic search for reverse isomers in natural diacylglycerophospholipids (Figure 11). For this purpose the glycerophospho- and glycolipids were dephosphorylated by phospholipase $\mathrm{C}$ and by periodate oxidation/hydrazinolysis, respectively. The released diacylglycerols were converted into the 3,5-DNPU derivatives, which were then resolved on the fully endcapped ODS columns (Superspher RP-18e, 

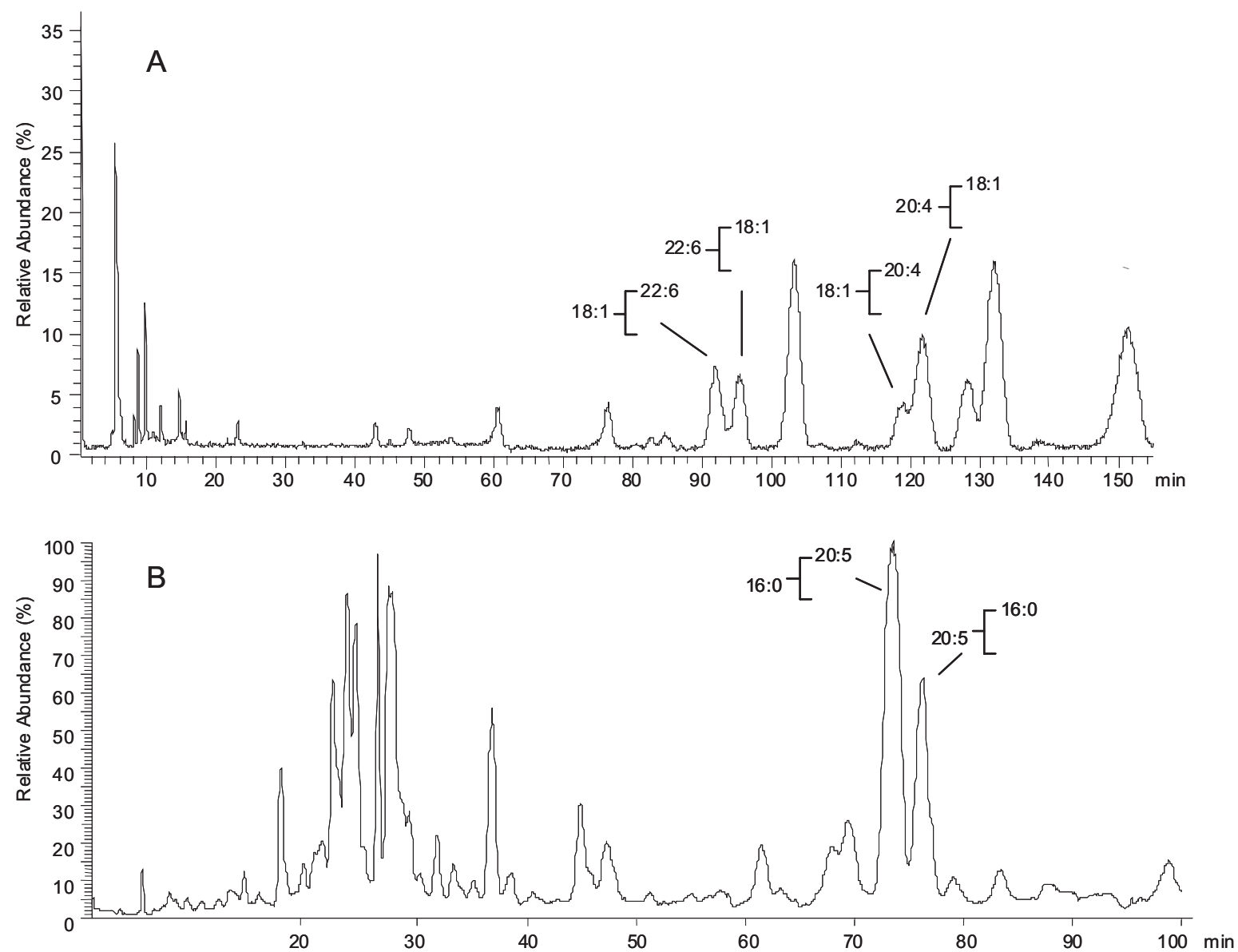

Figure 11. Reversed-phase HPLC/ESI-Ion Trap MS profiles (TIC chromatograms) of the 3,5-dinitrophenylurethane derivatives of 1,2-diacyl$s n$-glycerols derived from PtdEtn of human red cell (A) and monogalactosyldiacylglycerols of the red alga Porphyra yezoensis (B). Column: Superspher RP-18e (250 x 4 mm ID, $4 \mu \mathrm{m}$ particles). Other HPLC conditions as given in Figure 10.

250 x $4 \mathrm{~mm}$ ID, $4 \mu \mathrm{m}$ particles). Excellent reverse isomer separations were obtained (when present) for 18:0-22:6, 18:1-22:6, 18:020:5, 18:1-20:4, 18:1-20:5, 18:0-20:4, 16:0-22:6, 16:0-20:4, and 16:0-20:5 species $[4,69,70]$. The results confirmed the preferential location of saturated fatty acids in the $s n-1$ - and the polyunsaturated fatty acids in the $s n$-2-position as demonstrated by phospholipase $\mathrm{A}_{2}$ digestion. However, notable exceptions were also seen in mammalian samples, representing that several \% of the total phospholipid class (phosphatidylethanolamine, PtdEtn) was in the reverse isomer form (Figure 11 A). In contrast, the results also confirmed the preferential location of polyunsaturated fatty acids in the $s n$-1-position in seaweed glycolipids, representing that the relative content of 20:5-16:0 and 16:0-20:5 in total monogalactosyldiacylglycerols (MGDG) were $7.4 \%$ and $2.4 \%$, respectively (Figure 11 B). This method provided the first direct demonstration of the positional distribution of fatty acids in individual molecular species of natural glycerophospho- and glycolipids.

\subsection{Regioisomeric glycerophospholipids}

We have reported the direct chromatographic resolution of regioisomers of intact diacylglycerophospholipids [71] on the same reversed-phase column as that used for the resolution of the 3,5DNPU derivatives of diacylglycerols (Superspher RP-18e, 250 x 4 $\mathrm{mm}$ ID). Complete resolution was realized for the pairs of 1palmitoyl-2-docosahexaenoyl-sn- (16:0-22:6) and 1-docosahexaenoyl-2-palmitoyl-sn- (22:6-16:0), as well as for 1-palmitoyl2-eicosapentaenoyl-sn- (16:0-20:5) and 1-eicosapentaenoyl-2palmitoyl-sn- (20:5-16:0), and 1-palmitoyl-2-arachidonoyl-sn- (16: 0-20:4) and 1-arachidonoyl-2-palmitoyl-sn-glycero-3-phosphocholines (20:4-16:0). The separations were effected using acetonitrile/ methanol/water/triethylamine $(65: 30: 5: 0.1$, by vol) as the mobile phase.

\subsection{Regioisomeric triacylglycerols}

The determination of triacylglycerol regioisomers and enantiomers has always been a challenging analytical task. It plays an important part in the understanding of the role of triacylglycerol struc- 
ture in lipid metabolism and is essential for full characterization of triacylglycerols in lipid-containing foods and food additives. Resolution of regioisomeric triacylglycerols has been obtained only recently using highly efficient reversed-phase HPLC columns. We reported the resolution of some regioisomeric disaturated and monounsaturated triacylglycerols by reversed-phase HPLC [72]. A liquid chromatograph equipped with an evaporative light scattering detector (operating temperature $50^{\circ} \mathrm{C}, 2.4$ bar) and a fully endcapped Superspher 100 RP-18e column (250 x 4 mm ID, $4 \mu \mathrm{m}$ particles) was used. Three to six $\mu \mathrm{g}$ mixtures of the corresponding triacylglycerol isomers were injected using a $10 \mu \mathrm{L}$ injection loop. The analyses were performed isocratically at $18^{\circ} \mathrm{C}$ using mobile phases of acetonitrile modified with various solvents and at various flow rates as required. Regioisomeric pairs with saturated and unsaturated acyl groups were prepared by esterification of corresponding diacylglycerols and free fatty acids in the presence of $N, N$ -dicyclohexylcarbodiimide. Specifically separated triacylglycerol species were the following pairs: 1,3-dipamitoyl-2-oleoylglycerol (16:0-18:1-16:0)/1,2(2,3)-dipalmitoyloleoylglycerol (16:0-16:0-18: 1), 1,3-dipamitoyl-2-linoleoylglycerol (16:0-18:2-16:0)/1,2(2,3)dipalmitoyllinoleoylglycerol (16:0-16:0-18:2), 1,3-dipalmitoyl-2eicosapentaenoyglycerol (16:0-20:5-16:0)/1,2(2,3)-dipalmitoyleicosapentaenoylglycerol (16:0-16:0-20:5) and 1,3-dipalmitoyl-2docosahexaenoylglycerol (16:0-22:6-16:0)/1,2(2,3)-dipalmitoyldocosahexaenoylglycerol (16:0-16:0-22:6). The resolution improved with increasing number of double bonds in the acyl residues. While 16:0-18:1-16:0 and 16:0-16:0-22:6 were only partially resolved, 16:0-22:6-16:0 and 16:0-16:0-22:6 were fully separated with all tested mobile phases except those containing methanol. We also reported the separation of the regioisomeric 16:0-18:3-16:0/ 16:0-16:0-18:3 and 16:0-20:4-16:0/16:0-16:0-20:4 pairs of triacylglycerols on the Superspher RP-18e columns ( 250 x $4 \mathrm{~mm}$ ID, 4 $\mu \mathrm{m}$ particles) [73]. Separated species also included the four triacylglycerols with $\mathrm{ECN}=42:$ 16:0-20:5-16:0, 16:0-16:0-20:5, 16:0-22: 6-16:0, and 16:0-16:0-22:6, on a single reversed-phase HPLC column with mobile phase acetonitrile/2-propanol (70:30, by vol) at $0.8 \mathrm{~mL} / \mathrm{min}$. In all cases the isomer with the unsaturated acyl residue in either the 1- or 3-position was retained more strongly than the corresponding 2-isomer. This may be due to a residual polarity of the reversed-phase column, which would interact more strongly with the more polar unsaturated fatty acids located in the more accessible primary positions of the triacylglycerol molecule. Recently, Nagai et al. reported a rapid separation of regioisomeric triacylglycerols with two saturated fatty acids in the molecules using an octacosyl (C 28) column [74]. Good resolution has been achieved for 16:0-18:1-16:0/16:0-16:0-18:1, 16:0-22:6-16:0/16:016:0-22:6, and 16:0-18:1-18:0/18:1-18:0-16:0 within 30 min after injection using acetone as the mobile phase at $10-15^{\circ} \mathrm{C}$.

\section{Conclusion}

This review describes that chiral-phase and reversed-phase HPLC separations of synthetic mono- and diacylglycerol enantiomers and synthetic diacylglycerol reverse isomers, which we demonstrated in the 1980 s and 2000 s, respectively, can be readily extended to the resolution of naturally occurring enantiomeric mono- and diacylglycerols and regioisomeric acylglycerols derived from complex lipids. A combination of chiral-phase HPLC and reversed-phase HPLC with on-line MS permits the identification of the molecular species of enantiomers, diastereomers, and reverse isomers. A practical consequence of this development has been an accurate determination of the stereospecific positional placement of fatty acids in all glycerolipids. The development of improved CSP and reversed-phase columns along with optimized chromatographic elution conditions has permitted the further extension of chiralphase and reversed-phase HPLC resolution of enantiomers, diastereomers, and reverse isomers of intact glycerophospholipids. However, there still exist some compounds for which enantiomer resolution and regioisomer resolution are difficult to achieve, such as PtdCho and PtdEtn. With the development of new derivatization reagents and chromatographic techniques, these difficult compounds should not be hard to resolve in the near future. Organisms usually maintain the chirality of their constituents, but some exceptions have been recently found in amino acids and phospholipids. We believe that chiral-phase and reversed-phase HPLC will become much more important in the near future as a valuable tool for studying the physiological significance of enantiomers, diastereomers, and regioisomers of glycerolipids.

\section{Acknowledgements}

The author wishes to thank the late Professor Toru Takagi (Hokkaido University) and Professor Arnis Kuksis (University of Toronto) for their help and advice regarding the subject of this review. The author also thanks Professor Takao Tsuda (Nagoya Institute of Technology), Professor Kanji Miyabe (Toyama University) and Dr. Naobumi Oi (Chiralchromatography Laboratory) for their continued interest and encouragement. Thanks are due to all collaborators, co-workers, and colleagues of his studies.

Financial supports from the Ministry of Education, Science, Sports and Culture of Japan and the Research Fellowships of the Japan Society for the Promotion of Science, as well as from companies are gratefully acknowledged. The work in Canada was supported by the Heart and Stroke Foundation of Ontario, Toronto, Canada and the Medical Research Council of Canada, Ottawa.

Finally, the author is grateful to the Society for Chromatographic Science for selecting him as a recipient of the 2010 Award of the Society for Chromatographic Science. 


\section{References}

[1] Christie, W.W.; Han, X. In Lipid Analysis (4th ed.), The Oily Press, Bridgwater, England, 2010; Chapter 1.

[2] Han, X.; Gross, R.W. Proc. Natl. Acad. Sci. USA 1994, 91, 10635-10639.

[3] Kim, H.Y.; Wang, T.C.; Ma, Y.C. Anal. Chem. 1994, 66, 3977-3982.

[4] Kuksis, A.; Itabashi, Y. Methods 2005, 36, 172-185.

[5] Itabashi, Y.; Takagi, T. Lipids 1986, 21, 413-416.

[6] Itabashi, Y.; Myher, J.J.; Kuksis, A. J. Chromatogr. A 2000, 893, 261-279.

[7] Takagi, T. Prog. Lipid Res. 1990, 29, 277-298.

[8] Kuksis, A.; Marai, L.; Myher, J.J.; Itabashi, Y.; Pind, S. In Analysis of Fats, oils and lipoproteins; Perkins, E.G., Ed.; American Oil Chemists' Society, Champaign, IL, 1991; Chapters 13 and 25.

[9] Christie, W.W. In Advances in Lipid Methodology-One; Christie, W.W., Ed.; The Oily Press, Ayr, 1992; Chapter 4.

[10] Kuksis, A. In Advances in Lipid Methodology-Three; Christie, W.W., Ed.; The Oily Press, Ayr, 1996; Chapter 1.

[11] Itabashi, Y. Yukagaku 1998, 47, 971-981

[12] Itabashi, Y. Nippon Suisan Gakkaishi 2001, 67, 413-417.

[13] Itabashi, Y. In HPLC of Acyl Lipids; Lin, J.-T. ; McKeon T. A., Eds.; HNB Publishing, New York, 2005; Chapter 7.

[14] Kuksis, A.; Itabashi, Y. In Lipid Analysis and Lipidomics; Mossoba, M.; Kramer, J.K.G.; Brenna, J.T.; McDonald, R. E., Eds.; AOCS Press: Champaign, Illinois, 2006; Part II (4).

[15] IUPAC-IUB Commission on Biochemical Nomenclature. Eur. J. Biochem. 1967, 2, 127-131.

[16] Taylor, D.R.; Maher, K. J. Chromatogr. Sci. 1992, 30, 6785.

[17] Okabe, H.; Itabashi, Y.; Ota, T.; Kuksis, A. J. Chromatogr. A 1998, 829, 81-89.

[18] Okabe, H.; Itabashi, Y. Chromatography 1999, 20, 263-268.

[19] Pirkle, W.H.; Pochapsky, T.C. Chem. Rev. 1989, 89, 347362.

[20] Pirkle, W.H.; Mahler, G.; Hyun, M.H. J. Liq. Chromatogr. 1986, $9,443-453$.

[21] Eckert, H.; Forster, B. Angew. Chem. Int. Ed. Engl. 1987, 26, 894-895.

[22] Itabashi,Y; Takagi, T. J. Chromatogr. 1987, 402, 257-264.

[23] Oi, N.; Kitahara, H. J. Chromatogr. 1983, 265, 117-120.

[24] Oi, N.; Kitahara, H. J. Liq. Chromatogr. 1986, 9, 511-517.

[25] Takagi, T.; Ando, Y. Lipids 1990, 25, 398-400.

[26] Itabashi, Y.; Kuksis, A.; Marai, L.; Takagi, T. J. Lipid Res. 1990, 31, 1711-1717.

[27] Deng, L.; Nakano, H.; Iwasaki, Y. J. Chromatogr. A 2008,
1198-1199, 67-72.

[28] García, P.; Franco, P.; Álvarez, R.; de Lera, Á.R. J. Sep. Sci. 2011, 34, 999-1003.

[29] Itabashi, Y.; Kuksis, A. in 100 th AOCS Annual Meeting \& Expo, Orlando, May 3-6, 2009. Abstracts. p.16-17.

[30] Takagi, T.; Itabashi, Y. Lipids 1987, 22, 596-600.

[31] Suzuki, T.; Ota, T.; Takagi, T. J. Chromatogr. Sci. 1992, 30, 315-318.

[32] Itabashi, Y.; Myher, J.J.; Kuksis, A. J. Am. Oil Chem. Soc. 1993, 70, 1177-1181.

[33] Itabashi, Y.; Marai, L.; Kuksis, A. Lipids 1991, 26, 951-956

[34] Lehner, R.; Kuksis, A.; Itabashi, Y. Lipids 1993, 28, 29-34.

[35] Yang, L.Y.; Kuksis, A.; Myher, J.J.; Steiner, G. J. Lipid Res. 1995, 36, 125-136.

[36] Myher, J.J.; Kuksis, A.; Geher, K.; Park, P.W.; DiersenSchade, D.A. Lipids 1996, 31, 207-215

[37] Takahashi, T.; Itabashi, Y.; Suzuki, M.; Kuksis, A. Lipids 2001, 36, 741-748.

[38] Piyatheerawong, W.; Iwasaki, Y.; Yamane, T. J. Chromatogr. A 2005, 1068, 243-248.

[39] Kodali, D.R.; Tercyak, A.; Fahey, D.A.; Small, D.M. Lipids 1990, 52, 163-170.

[40] Iwasaki, Y.; Yasui, M.; Ishikawa, T.; Irimescu, R.; Hata, K.; Yamane, T. J. Chromatogr. A 2001, 905, 111-118.

[41] Nagai, T.; Mizobe, H.; Otake, I.; Ichioka, K.; Kojima, K.; Matsumoto, Y.; Gotoh, N.; Kuroda, I.; Wada, S. J. Chromatogr. A 2011, 1218, 2880-2886.

[42] Itabashi, Y.; Takagi, T.; Tsuda, T. J. Chromatogr. 1989, 472, 271-276.

[43] Takagi, T.; Itabashi, Y.; Tsuda, T. J. Chromatogr. Sci. 1989, 27, 574-577

[44] Itabashi, Y.; Tsuda, T. Bunseki Kagaku 2000, 49, 10331036.

[45] Itabashi, Y. ; Kuksis, A ; Myher, J.J. J. Lipid Res. 1990, 31, 2119-2126.

[46] Marai, L.; Kuksis, A.; Myher, J.J.; Itabashi, Y. Biol. Mass Spectrom. 1992, 21, 541-547.

[47] Itabashi, Y.; Kuksis, A. Anal. Biochem. 1997, 254, 49-56.

[48] Sato, R.; Itabashi, Y.; Hatanaka, T.; Kuksis, A. Lipids 2004, 39, 1013-1018.

[49] Sato, R.; Itabashi, Y.; Suzuki, A.; Hatanaka, T.; Kuksis, A. Lipids 2004, 39, 1019-1023.

[50] Sato, R.; Itabashi, Y.; Fujishima, H.; Okuyama, H.; Kuksis, A. Lipids 2004, 39, 1025-1030.

[51] Itabashi, Y.; Fujishima, H.; Sato, R. J. Oleo Sci. 2004, 53, 405-412.

[52] Fujishima, H.; Gamano, T.; Taoka, Y.; Sawabe, T.; Itabashi, Y. Nippon Suisan Gakkaishi 2004, 70, 200-202. 
[53] Gamano, T.; Fujishima, H.; Sawabe, T.; Itabashi, Y. Bull. Fish. Sci. Hokkaido Univ. 2004, 55, 17-21.

[54] Itabashi, Y.; Kuksis, A. In 98 th AOCS Annual Meeting \& Expo, Quebec, May 13-16, 2007. Abstracts. p.10.

[55] Itabashi, Y.; Ebata, T.; Hatanaka, A.; Kuksis, A. In 95 th AOCS Annual Meeting \& Expo, Cincinnati, May 9-12, 2004. Abstracts. p.3-4.

[56] Omori, T.; Mihara, H.; Kurihara, T.; Esaki, N. Biochem. Biophys. Res. Commun. 2009, 382, 415-418.

[57] Kates, M. Prog. Chem. Fats other Lipids 1978, 15, 301-342.

[58] Benveniste, J.; Vargaftig, B.B. In Ether Lipids, Mangold, H. K.; Paltauf, F. Eds., Academic Press, New York, 1983, Chapter 18.

[59] Takagi, T.; Itabashi, Y. J. Chromatogr. 1986, 366, 451-455.

[60] Itabashi, Y.; Yamaguchi, A.; Nakaya, K. In Biology of the Megamouth Shark; Yano, K.; Morrissey, J.F.; Yabumoto, Y.; Nakaya, K. Eds.; Tokai University Press, Tokyo, 1997, pp. 151-159.

[61] Yamashina, T.; Lee, J.-S.; Itabashi, Y. Bunseki Kagaku 2006, 55, 643-650.

[62] Takagi, T.; Okamoto, J.; Ando, Y.; Itabashi, Y. Lipids 1990, $25,108-110$

[63] Itabashi, Y.; Kuksis, A. In 95 th AOCS Annual Meeting \& Expo, Quebec, May 5-8, 2002. Abstracts S 13.

[64] Marathe, G.K.; Silva, A.R.; de Castro, H.C.; Neto, F.; Tjoelker, L.W.; Prescott, S.M.; Zimmerman, G.A.; McIn- tyre, T.M. J. Lipid Res. 2001, 42, 1430-1437.

[65] Matthaus, B. Eur. L. Lipid Sci. Technol. 2011, 113, 277278.

[66] Masukawa, Y., Shiro, H.; Kondo, N.; Kudo, N. J. Am. Oil Chem. Soc. 2011, 88, 15-21.

[67] Yoshioka, S.; Nishimura, K.; Suzuki, T.; Takamura, T.; Suzui, M.; Tsuda, H.; Itabashi, Y. Chromatography 2010, Supplement 1, 53-54.

[68] Aizawa, C.; Shiozaki, R.; Itabashi, Y. Bunseki kagaku 2007, 56, 833-839.

[69] Itabashi, Y.; Kuksis, A. In 24 th World Congress and Exhibition of ISF, Berlin, September 16-20, 2002. Abstracts S 13.

[70] Itabashi, Y. In Proceedings of the 3 rd Japan-Korea Joint Seminar on Fisheries Sciences, Jinju-Tongyeong, Dec. 1516, 2003. pp.161-164.

[71] Kuksis, A.; Itabashi, Y. In 95 th AOCS Annual Meeting \& Expo, Cincinnati, May 9-12, 2005. Abstracts p. 3.

[72] Momchilova, S.; Tsuji, K.; Itabashi, Y.; NikolovaDamyanova, B.; Kuksis, A. J. Sep. Sci. 2004, 27,1033-1036.

[73] Momchilova, S.; Itabashi, Y.; Nikolova-Damyanova, B.; Kuksis, A. J. Sep. Sci. 2006, 29, 2578-2583.

[74] Nagai, T.; Gotoh, N.; Mizobe, H.; Yoshibaga, K.; Kojima, K.; Matsumoto, Y.; Wada, S. J. Oleo Sci. 2011, 60, 345350 . 